\title{
Atypical patterns of the de Winter sign: even more confusion in clinical practice
}

\author{
Kenan Yalta', Ugur Ozkan', Ertan Yetkin² \\ 'Cardiology Department, Trakya University, Edirne, Turkey \\ ${ }^{2}$ Cardiology Department, Derindere Hospital, Istanbul, Turkey
}

\author{
Correspondence to: \\ Kenan Yalta, MD, \\ Cardiology Department, \\ Trakya University, \\ Edirne 22030, Turkey, \\ phone: +90 5056579856, \\ e-mail: \\ akenanyalta@trakya.edu.tr \\ Copyright by the Author(s), \\ 2021 \\ Kardiol Pol. 2021; \\ 79 (7-8): 897-898; \\ DOI: 10.33963/KP.a2021.0049 \\ Received: \\ May 31, 2021 \\ Revision accepted: \\ June 6, 2021 \\ Published online: \\ June 27, 2021
}

\section{TO THE EDITOR}

Over recent years, the de Winter sign has attracted a particular interest as an important equivalent of anterior ST segment elevation myocardial infarction (STEMI) [1-3]. This electrocardiographic (ECG) phenomenon generally presents with certain changes in the precordial leads (primarily characterized by J point depression along with prominent "T waves" mostly located in leads V2 and V3) accompanied by a slight ST segment elevation in aVR $[2,3]$. Basically, the de Winter sign has been ascribed to potential factors including severe transmural ischemia and conduction defects [2]. Importantly, it strongly mimics ECG findings of relatively non-emergent acute coronary syndromes (ACSs) with ST segment depression, potentially necessitating a high index of suspicion for its diagnosis [2, 3]. In their recently published article, Theodoropoulos et al. [1] have reported an interesting de Winter sign in a young male. Accordingly, we would like to make a few comments on their case and further implications of the de Winter sign in clinical practice.

First, the authors have considered their case as a combined presentation of hyperacute $T$ waves and the de Winter sign [1]. However, we hold the opinion that this case might be labeled as an atypical pattern of the de Winter sign primarily manifesting as prominent $T$ waves in the leads V1-V3 and J point depression in the leads V4 and V5. In other terms, T wave changes and $J$ point depression in this patient did not concur on the same precordial derivations as usually expected, yet emerged in a consecutive manner [1]. Possibly owing to the subtle and intricate ECG findings in the case, there is reportedly a missed STEMI diagnosis on admission [1]. Fortunately, the case seems to have had a spontaneous reperfusion of the culprit coronary artery soon after hospitalization [1].

In the clinical context, evolution of an atypical de Winter sign might be due to certain anatomical factors or pre-existing ECG changes, and signifies a broad range of changes in the pattern and predilection site of the classical de Winter criteria [2]. For instance; an atypical de Winter sign might present with widespread, inferior or inferolateral ST segment or J point depressions, and might not necessarily lead to usual changes in the lead aVR [2]. Therefore, definition of an atypical de Winter sign has not been uniform so far potentially creating a substantial diagnostic confusion as compared with its classical counterpart [2]. In this context, we previously reported an atypical de Winter sign (in a young male patient) that had a strong analogy to the ECG findings of left main coronary artery (LMCA) stenosis (presenting with a widespread ST segment depression that proved to be due to the acute left anterior descending artery occlusion on coronary angiogram [CAG]) [3]. Based on our observations, there might be two common ECG patterns of an atypical de Winter sign that might mandate emergent CAG as well:

- Widespread ST segment depression (a potential mimic of critical LMCA stenosis);

- J point depression in at least two contiguous leads (regardless of their location and other accompanying manifestations including $\mathrm{T}$ wave changes, etc.).

Second, a classical de Winter sign and characteristic ST segment elevation in the precordial leads might arise in an alternating fashion in some de Winter cases, particularly in the pre-reperfusion setting [2]. Moreover, intermittent episodes of ST segment elevation appear to be more frequent in those with an atypical 
de Winter sign [2]. Accordingly, we wonder whether the patient [1] had a persistent de Winter sign (namely static form) [2] before the resolution of his pain.

Finally, gradual resolution of the patient's chest pain after his admission potentially suggests a spontaneous reperfusion of the left anterior descending artery [1]. Interestingly, the subsequent ECGs were reported to be similar to the initial ECG [1]. This denotes that an atypical de Winter sign might possibly persist for some time even after reperfusion of the associated coronary artery. Therefore, one should not draw firm conclusions on the reperfusion status prior to CAG exclusively based on the evaluation of this ECG phenomenon. However, transition to the characteristic subacute STEMI pattern eventually ensues mostly with the evolution of pathologic Q waves on ECG [4] (as evident on the second day and predischarge ECGs of the patient [1]).

In summary, the de Winter sign, besides its classical form, might also present with a variety of atypical patterns potentially rendering the evaluation of STEMI even more challenging [2,3]. In this context, there exists an absolute necessity to fully outline the ECG features and practical implications of these atypical patterns in the clinical setting.

\section{Article information}

Conflict of interest: None declared.

Open access: This article is available in open access under Creative Common Attribution-Non-Commercial-No Derivatives 4.0 International (CC BY-NC-ND 4.0) license, allowing to download articles and share them with others as long as they credit the authors and the publisher, but without permission to change them in any way or use them commercially. For commercial use, please contact the journal office at kardiologiapolska@ptkardio.pl.

How to cite: Yalta K, Ozkan U, Yetkin E. Atypical patterns of de Winter sign: Even more confusion in clinical practice. Kardiol Pol. 2021; 79(7-8): 897-898, doi: 10.33963/KP.a2021.0049.

\section{References}

1. Theodoropoulos KC, Ziakas A, Kadoglou NPE, et al. Combination of hyperacute T waves and de Winter sign in precordial leads: a hybrid pattern equivalent to ST-segment elevation? Kardiol Pol. 2021; 79(4): 477-478, doi: 10.33963/KP.15926, indexed in Pubmed: 33843177.

2. Yalta K, Yetkın E, Taylan G. de Winter pattern: Is it always so typical? Rev Port Cardiol. 2021; 40(3): 249-250, doi: 10.1016/j.repce.2020.10.018.

3. Gurdogan M, Yalta K, Altay S, et al. Atypical 'de Winter pattern' mimicking acute left main coronary artery lesion. North Clin Istanb. 2020; 7(6): 619-620, doi: 10.14744/nci.2020.68790, indexed in Pubmed: 33381703.

4. Paixão-Ferreira M, Rocha AR, Piçarra B, et al. De Winter pattern: An ST-elevation myocardial infarction equivalent. Rev Port Cardiol. 2020; 39(10): 613-614, doi: 10.1016/j.repc.2019.09.020, indexed in Pubmed: 32919828. 